\title{
MAP SHOWING BEDROCK TOPOGRAPHY BENEATH ALLUVIAL DEPOSITS OF THE CALHOUN QUADRANGLE, WESTERN KENTUCKY \\ By \\ Avery E. Smith
}
MISCELLANEOUS GEOLOGIC INVESTIGATIONS
MAP I-906

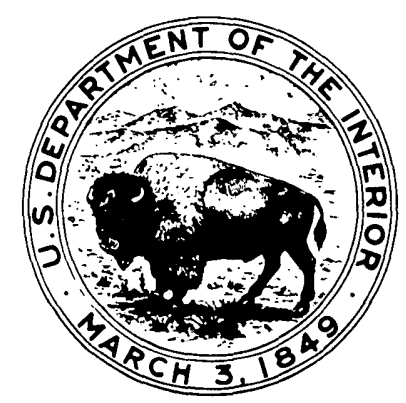

